\title{
GEOSUL
}

\section{DELMIRO GOUVEIA: UM EMPRESÁRIO SCHUMPETERIANO E SEU LEGADO NA ORGANIZAÇÃO ESPACIAL DO SERTÃO ALAGOANO}

\author{
Bruno Bianchi Gonçalves da Silva ${ }^{1}$ \\ Domingos Sávio Corrêa ${ }^{2}$
}

\begin{abstract}
Resumo: Delmiro Augusto da Cruz Gouveia foi assassinado em 1917, na antiga Vila da Pedra, povoação onde desenvolveu seus negócios de couros e linhas em terras alagoanas. Sua ação pioneira em construir uma usina hidrelétrica no rio São Francisco serve, anos mais tarde, de inspiração para criação da Companhia Hidro Elétrica do São Francisco (CHESF), não o bastante, seu pioneirismo se repete ao trazer para o sertão uma fábrica têxtil. Cem anos após o assassinato, suas iniciativas com traços modernizantes foram decisivas para o atual município de Delmiro Gouveia, que leva seu nome, ser o principal município da mesorregião do Sertão Alagoano, em termos populacionais e econômicos. O trabalho utiliza como referencial teórico os conceitos de empresário e empreendimento do economista Joseph Schumpeter; e na organização espacial do município, as categorias de análise do espaço, por Milton Santos.
\end{abstract}

Palavras-chave: Delmiro Gouveia; Empresário; Empreendimento; Organização espacial

\section{DELMIRO GOUVEIA: A SCHUMPETERIAN ENTREPRENEUR AND HIS LEGACY IN THE SPATIAL ORGANIZATION OF THE SERTÃO ALAGOANO}

\begin{abstract}
Delmiro Augusto da Cruz Gouveia was assassinated in 1917, in the old Vila da Pedra, a village where he developed his business of leathers and lines in Alagoas lands. Its pioneering action to build a hydroelectric power plant on the São Francisco river, years later, inspired the creation of the Hydroelectric Company of São Francisco (CHESF), not enough, its pioneerism is repeated when bringing to the hinterland a textile factory. One hundred years after the assassination, his initiatives with modernizing features were decisive for the current municipality of Delmiro Gouveia, which bear his name, to be the main municipality of the Sertão Alagoano mesoregion in population and economic terms. The work uses as theoretical reference the concepts of entrepreneur and enterprise of the economist Joseph Schumpeter; and in the spatial organization of the municipality, the categories of space analysis, by Milton Santos.
\end{abstract}

Keywords: Delmiro Gouveia; Entrepreneur; Enterprise; Spatial organization

\section{DELMIRO GOUVEIA: UN EMPRESARIO SCHUMPETERIANO Y SU LEGADO EN LA ORGANIZACIÓN ESPACIAL DEL SERTÃO ALAGOANO}

Resumen: Delmiro Augusto da Cruz Gouveia fue asesinado en 1917, en la antigua Vila da Pedra, pueblo donde desarrolló sus negocios de cueros y líneas en tierras alagoanas. Su acción pionera en construir una planta hidroeléctrica en el río San Francisco sirve, años más tarde, de

\footnotetext{
${ }^{1}$ Mestrando do Programa de Pós-Graduação em Geografia da UFAL. Email: bruno bianchi1@ @ hotmail.com

2 Doutor em Geografia pela USP. Professor do Programa de Pós-Graduação em Geografia da UFAL. Email: saviocorrea642@gmail.com
} 
inspiración para la creación de la Compañia Hidroeléctrica de San Francisco (CHESF), no lo suficiente, su pionerismo se repite al traer al sertón una fábrica textil. Cien años después del asesinato, sus iniciativas con rasgos modernizantes fueron decisivas para el actual municipio de Delmiro Gouveia, que lleva su nombre, ser el principal municipio de la mesorregión del Sertão Alagoano, en términos poblacionales y económicos. El trabajo utiliza como referencial teórico los conceptos de empresario y emprendimiento del economista Joseph Schumpeter; Y en la organización espacial del municipio, las categorías de análisis del espacio, por Milton Santos.

Palabras clave: Delmiro Gouveia; Empresario; Emprendimiento; Organización espacial

\section{INTRODUÇÃO}

Este trabalho analisa os aspectos da organização espacial no município de Delmiro Gouveia-AL, ao enfocar os objetos técnicos determinantes na estruturação urbana do município, sendo eles, a Estrada de Ferro Paulo Afonso, a Usina Hidrelétrica de Angiquinho e a fábrica de linhas. Busca mostrar que a partir do pioneirismo do empresário Delmiro Gouveia na industrialização do sertão nordestino, a região não se resume a seca e a caatinga, para além disso, é uma região promissora e que já foi palco de ações inéditas.

Será abordada brevemente a história de Delmiro Gouveia, com o intuito de traçar a sua chegada até o estado de Alagoas, entretanto, este não é um trabalho biográfico. Para isso, existem obras que cumprem muito bem tal objetivo, trazendo com riqueza de detalhes a sua vida pessoal e empresarial, a exemplo dos livros: "Delmiro Gouveia: o pioneiro de Paulo Afonso", de Tadeu Rocha (1963) e, "Delmiro Gouveia: o Mauá do sertão alagoano", de Félix Lima Júnior (1963). Traços de sua personalidade e empreendimentos estão presentes também no cinema e na música, através do filme "Coronel Delmiro Gouveia", de Geraldo Sarno (1977), e do baião "Paulo Afonso", gravado em 1955, por Luiz Gonzaga e Zé Dantas.

O trabalho divide-se em quatro tópicos, o primeiro, fará um breve levantamento da trajetória de Delmiro Gouveia até o estado de Alagoas. Já o segundo, de cunho teórico, trará os conceitos de empresário e empreendimento a partir da visão de Joseph A. Schumpeter e as iniciativas de Delmiro Gouveia inseridas nessa interpretação.

O terceiro tópico, também de cunho teórico, mostrará brevemente, as categorias de análise do espaço geográfico, propostas por Milton Santos em seu livro "Espaço e Método" (1985), sendo elas: forma, função, estrutura e processo, servindo de suporte para o quarto tópico, onde se discutirá os aspectos da organização espacial do município de Delmiro Gouveia (antiga Vila da Pedra), em Alagoas, entre o final do século XIX e começo do século XX. 
Além disso, no início do quarto tópico, abordará a instalação da ferrovia no município, época em que era uma vila remota, por considerá-la importante em sua estruturação urbana e também por ter um elo com Delmiro Gouveia, pois, atualmente, o prédio da estação ferroviária abriga um museu em sua memória.

\section{A RESILIÊNCIA DO 'INDUSTRIAL DO SERTÃ̃'}

Delmiro Augusto da Cruz Gouveia, mais conhecido por Delmiro Gouveia, nasceu no antigo distrito de Ipu (atual município de Sobral), no estado do Ceará, em 5 de junho de 1863. Testemunhou a transição do Império para a República, o primeiro surto industrial brasileiro, nas duas últimas décadas do século XIX, e estabeleceu laços com a elite nordestina, principalmente em Pernambuco e Alagoas, estados onde instalou seus empreendimentos.

A partir dos 18 anos, já na cidade do Recife, Delmiro Gouveia passa a trabalhar em ramos que certamente influenciaram sua trajetória empresarial. Desde então, trabalhou em armazém de algodão como despachante de barcaças e, logo depois, começa sua carreira no comércio de couros e peles em 1885 (ALVES, 2014).

Continuando suas investidas no pujante ramo de compra e venda de couros e peles, Delmiro vê seu rápido enriquecimento e ainda no final do século XIX detêm o monopólio deste comércio no Recife. Estendendo os tentáculos de seu comércio de Minas Gerais ao Piauí, se consolida no ramo e passa a ser conhecido como o 'rei das peles', alcançando forte influência na Associação Comercial de Pernambuco (ROCHA, 2012; ALVES, 2014).

O incômodo com o sucesso e influência de Delmiro Gouveia no meio políticoempresarial culmina com o incêndio de grandes proporções no Mercado do Derby no início de 1900, construído por ele no ano anterior. A perseguição política e econômica torna a sua permanência arriscada e insustentável em Pernambuco, obrigando-o a deixar o estado e mudar-se para Alagoas.

Em 1903, chega ao estado vizinho sendo acolhido pela oligarquia local e torna-se proprietário de uma fazenda na Vila da Pedra, um povoado praticamente inóspito no Sertão Alagoano. Delmiro era um empresário experiente e de visão inovadora, não foi à toa que reestabeleceu seus negócios na longínqua povoação da Pedra, distante cerca de $300 \mathrm{~km}$ de Maceió, capital de Alagoas. A então denominada Vila da Pedra situava-se a poucos quilômetros do rio São Francisco, na divisa com os estados de Sergipe, Bahia e Pernambuco, além de dispor de uma estação da Estrada de Ferro Paulo Afonso que ligava os municípios sertanejos entre Piranhas-AL e Petrolândia-PE (ROCHA, 2012; ALVES, 2014).

A região já tinha como tradição o comércio de couros e peles, desde o início de sua 
colonização, a partir de 1769. A atividade comercial foi a principal responsável pelo enriquecimento de Delmiro, com o valor em dinheiro de suas exportações sempre superior as exportações de linhas (SANT'ANA, 1996).

Na década seguinte, foram inauguradas a Usina Hidrelétrica de Angiquinho e a fábrica de linhas, respectivamente, em 1913 e 1914, em terras cedidas pelo governo de Alagoas (SANT'ANA, 1996). Após esse feito e empregando mão-de-obra sertaneja, entre diversas denominações atribuídas a figura de Delmiro Gouveia, este passa a ser conhecido também como o "Industrial do Sertão".

O desenvolvimento da economia na Vila da Pedra permitiu a criação do Distrito da Pedra por Decreto Estadual de 1938, subordinado até então ao município de Água Branca. Poucos anos mais tarde, em 1943, o Distrito passa a denominar-se Delmiro Gouveia, em homenagem ao homem que trouxe o progresso para este lugar. Finalmente, em 1952, o Distrito é desmembrado de Água Branca e elevado à categoria de município por Lei Estadual, denominando-se município de Delmiro Gouveia, ver Figura 1 (ENCICLOPÉDIA DOS MUNICÍPIOS BRASILEIROS, 1957).

Um aspecto de sua vida empresarial que merece ser destacado é a sua resiliência; superando dificuldades, se reinventando e sempre buscando diversificar a atuação econômica. Entre os traços de sua personalidade, o temperamento volúvel, o discurso nacionalista e da ideologia do trabalho são as características que mais lhe são atribuídas em obras que abordam sua vida pessoal e empresarial.

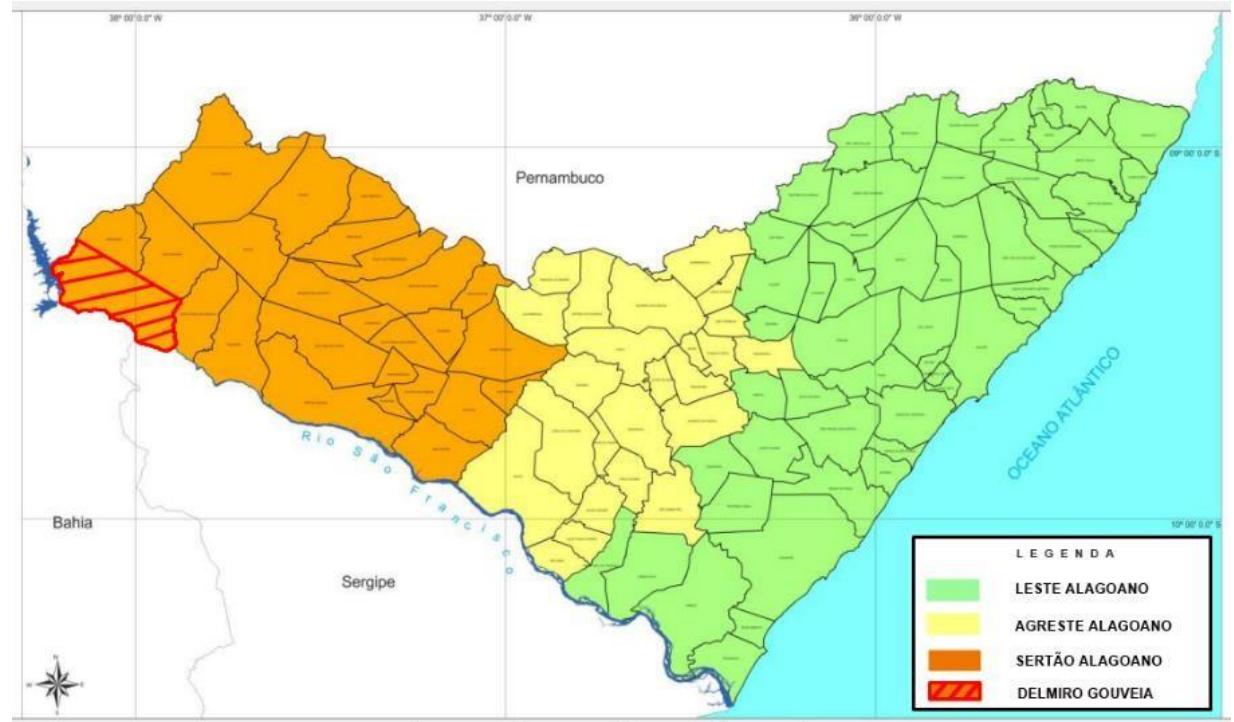

Figura 1: Mesorregiões do estado de Alagoas e localização do município de Delmiro Gouveia, em destaque.

Fonte: Secretaria de Estado do Planejamento e do Desenvolvimento Econômico, 2012 (Adaptado).

A trajetória de Delmiro Gouveia acaba na noite do dia 10 de outubro de 1917, quando 
estava em seu chalé na Vila da Pedra e foi alvejado por tiros, morrendo aos 54 anos. Os suspeitos do crime nunca foram encontrados (SANT'ANA, 1996).

Passada sua fase áurea, a fábrica de linhas começa a ter dificuldades de financiamento e na concorrência com a estrangeira Machine Cottons sendo vendida, em 1927, à empresa pernambucana Menezes Irmãos e Cia., detentoras de uma fábrica têxtil em seu estado. Com o agravante da Grande Depressão de 1929, o maquinário mais moderno da fábrica foi vendido para Machine Cottons. A fábrica de linhas que chegou a empregar de 800 a 1.000 operários na década de 1920, na década seguinte, em 1934, contava com apenas 500 operários (LIMA JÚNIOR, 1983; ROCHA, 2012).

Observando os dados da Tabela 1, no ano de 1922, a fábrica de linhas estava entre as quatro que mais empregavam no ramo de fiação e tecelagem em Alagoas. Considerando o fato da fábrica de linhas ter sido instalada 20 anos depois que as três primeiras colocadas (em número de operários) e já possuir mais de 800 operários, constata-se, nesse período entre as décadas de 1910 e 1920, seu rápido crescimento no mercado têxtil.

Tabela 1: Número de operários em 1922 e datas de abertura e fechamento das fábricas têxteis em Alagoas*

\begin{tabular}{|l|c|c|c|}
\cline { 2 - 4 } \multicolumn{1}{l|}{} & Município & Operários & Abertura/Fechamento \\
\hline Fábrica Cachoeira & Rio Largo & 1112 & 1893 - anos 1970 \\
\hline Cia. União Mercantil & Maceió & 850 & 1863 - 2010 \\
\hline Fábrica Progresso & Rio Largo & 810 & 1890 - anos 1970 \\
\hline Fábrica de Linhas & $\begin{array}{c}\text { Delmiro } \\
\text { Gouveia }\end{array}$ & Mais de 800 & 1914 - \\
\hline Fábrica Penedense & Penedo & 500 & 1898 - ... \\
\hline Fábrica Alexandria & Maceió & 300 & $1911-$ anos 1950 \\
\hline $\begin{array}{l}\text { Cia. Fiação e Tecidos } \\
\text { São Miguel }\end{array}$ & $\begin{array}{l}\text { São Miguel } \\
\text { dos Campos }\end{array}$ & 300 & 1913 - ... \\
\hline Fábrica Pilarense & Pilar & $180 * *$ & $1893-$ anos 1960 \\
\hline
\end{tabular}

Fonte: MARROQUIM, 1922; LESSA, 2013.

(*) Informações de 8 fábricas têxteis, do ramo de fiação e tecelagem, em um total de 12 existentes nos anos 1920.

(**) Dado de 1902.

(...) Não disponível.

Apesar da morte do 'Industrial do Sertão', a fábrica de linhas permaneceu em operação e o atual município de Delmiro Gouveia seguiu com o seu crescimento comercial e urbano; “em 1956, funcionavam 160 pequenas fábricas de rede, sendo 'Delmiro' o município maior produtor do artigo no Estado" (LIMA JÚNIOR, 1983, p. 287). 


\section{DELMIRO GOUVEIA SOB A ÓTICA DO EMPRESÁRIO SCHUMPETERIANO}

A expressão 'empresário schumpeteriano' deriva da obra "Teoria do Desenvolvimento Econômico", do economista austríaco Joseph A. Schumpeter que através de sua visão global da economia destaca a importância do empresário inovador para o desenvolvimento econômico, inserindo assim, o papel da inovação tecnológica como motor do desenvolvimento capitalista. Em seu prefácio à edição inglesa, Schumpeter alerta que esta obra é de cunho "teórico" em seu objetivo e método.

Para situar o papel de Delmiro Gouveia como empresário schumpeteriano, este trabalho utiliza a obra "Teoria do Desenvolvimento Econômico", focando em seu capítulo II, intitulado 'O fenômeno fundamental do desenvolvimento econômico', onde aborda o papel da inovação na economia.

Schumpeter apresenta a economia baseada num fluxo circular que se repete, de caráter "estático", no capítulo I da obra. Em contraste, no capítulo seguinte, apresenta um fator dinâmico nesse processo, que muda o fluxo contínuo e vem de dentro da própria economia; é a atuação do empresário inovador, aplicando técnicas modernas ou inovando tecnologicamente, essa inovação, é o motor do desenvolvimento econômico. Afirma ainda que "essas mudanças espontâneas e descontínuas no canal do fluxo circular e essas perturbações do centro do equilíbrio aparecem na esfera da vida industrial e comercial (SCHUMPETER, 1997, p. 75).

Diferenciando do conceito dado pela economia tradicional e como é atribuído costumeiramente, na interpretação de Schumpeter, a figura do empresário não é apenas daquele sujeito responsável pela administração de sua empresa. Segundo ele, nessa fase, o empresário ainda não é inovador e, caso permaneça limitado a isso, não faz grandes fortunas e não ascende socialmente. Para além disso, seu conceito de empresário é o indivíduo que realiza novas combinações. “Chamamos 'empreendimento' à realização de combinações novas; chamamos 'empresários' aos indivíduos cuja função é realizá-las” (SCHUMPETER, 1997, p. 83).

Consideramos aqui como empreendimento de Delmiro Gouveia, a Usina Hidrelétrica de Angiquinho e a fábrica de linhas gerando combinações inéditas no sertão nordestino, ao introduzir na região a atividade têxtil e o uso de energia elétrica. Para se ter uma ideia, a inauguração da energia elétrica nos limites do Sertão Alagoano, em 1913, se deu "[...] antes que a cidade do Recife, metrópole do Nordeste, começasse a possuir serviços públicos de iluminação[...]" (ROCHA, 2012, p. 138). O pioneirismo de Delmiro em explorar a força das 
águas do São Francisco produzindo eletricidade, anos mais tarde, serve de inspiração para criação da Companhia Hidro Elétrica do São Francisco (CHESF), em 1945, durante o Governo Vargas. Somente após a criação da CHESF, o fornecimento de energia elétrica torna-se generalizado em Alagoas, com o surgimento do Plano de Eletrificação e da Companhia de Eletricidade de Alagoas (CEAL), sob o governo de Muniz Falcão (19561961). Nesse período, dos 41 municípios alagoanos somente quatro recebiam energia elétrica da CHESF$^{3}$ (PAIVA FILHO, 2013; TICIANELI, 2016).

Com o fornecimento de eletricidade na antiga Vila da Pedra, sua fábrica de linhas era a única fábrica têxtil em Alagoas que utilizava exclusivamente energia elétrica para mover suas máquinas, as demais, utilizavam energia hidráulica e a vapor, pelo menos, até a década de $1950^{4}$.

Consideramos também, o perfil de Delmiro Gouveia como empresário dentro dos moldes da visão de Schumpeter, que destaca três características principais desse indivíduo: a iniciativa, a autoridade e a previsão (SCHUMPETER, 1997). Ainda quando morava em Recife, viajou aos Estados Unidos para visitar a Exposição Universal de Chicago de 1893, sinônimo do progresso tecnológico e científico, onde a nação norte-americana buscava mostrar como um país fora da Europa se tornou uma nação moderna e industrializada. Viajou diversas vezes a Europa, berço da inovação e cultura mundial até o começo do século XX (ALVES, 2014; GIMENES, 2014).

Schumpeter comenta que a capacidade inovadora do empresário é independe do tempo histórico:

O tipo moderno de 'capitão de indústria' corresponde mais estritamente ao que queremos expressar aqui, especialmente se se reconhece, por um lado, a sua identidade, digamos, com o empresário comercial da Veneza do século XII — ou, entre os tipos mais modernos, com John Law - e, por outro, com o potentado da aldeia que combina a sua agricultura e o seu comércio de gado, digamos, com uma cervejaria rural, um hotel, uma loja (SCHUMPETER, 1997, p. 86).

Um fator fundamental às ações inovadoras do empresário é o crédito. Schumpeter nos mostra a importância dos bancos ao financiar o desenvolvimento fornecendo o crédito, criando assim, um poder de compra que o empresário não possuía. Ainda no segundo capítulo de sua obra, comenta a princípio, a função do crédito:

Esse método de obter dinheiro é a criação de poder de compra pelos bancos [...] É sempre uma questão não de transformar o poder de compra que já existe em propriedade de alguém, mas da criação de novo poder de compra a partir do nada -

\footnotetext{
${ }^{3}$ Atualmente o estado de Alagoas possui 102 municípios.

${ }^{4}$ As fábricas têxteis Cachoeira e Progresso, no município de Rio Largo, utilizavam energia elétrica para mover parte de seu maquinário, porém, a eletricidade era utilizada de forma consorciada com as fontes de energia hidráulica e a vapor.
} 
a partir do nada mesmo que o contrato de crédito pelo qual é criado o novo poder de compra seja apoiado em garantias que não sejam elas próprias meio circulante que se adiciona à circulação existente (SCHUMPETER, 1997, p. 82).

O crédito não vem de dentro do sistema produtivo e tem uma natureza imaterial, esse poder de compra foi fundamental para Delmiro Gouveia entrar no comércio de peles e couros em Recife, e na recuperação econômica e instalação dos seus empreendimentos no Sertão Alagoano. O aporte financeiro era obtido com a firma L. H. Rossbach \& Brothers, de Nova York. Possivelmente, sua ação empreendedora seria inviabilizada caso não tivesse acesso ao crédito (ROCHA, 2012; ALVES, 2014).

\section{SÍNTESE DAS CATEGORIAS DE ANÁLISE DA ORGANIZAÇÃO ESPACIAL: FORMA, FUNÇÃO, ESTRUTURA E PROCESSO}

Milton Santos no auge do movimento crítico da geografia publica, em 1978, "Por uma Geografia Nova”, onde propõe uma teoria espacial para esta ciência. Considera o espaço geográfico como produto das relações sociais, sendo ele simultaneamente produtor e produto. "Quando se admite que o espaço é um fato social, é o mesmo que recusar sua interpretação fora das relações sociais que o definem" (SANTOS, 2004, p. 163).

Para analisar o espaço em sua totalidade e no tempo, Milton Santos elenca quatro categorias analíticas da organização espacial, são elas: forma, função, estrutura e processo. Em seu livro "Espaço e Método", publicado pela primeira vez em 1985, encontramos as definições e discussões dessas categorias.

Forma é o aspecto visível do objeto, podendo ser uma escola, um prédio, uma indústria; já a função, que está diretamente ligada com sua forma, é a atividade exercida por este objeto, sua finalidade é atribuída pela necessidade da sociedade. Estrutura é o modo de organização ou construção. Processo é uma ação contínua, sendo relacionado a tempo e mudança (SANTOS, 1997; SANTOS 2014).

Explica que essas categorias não devem ser analisadas isoladamente, elas estão associadas e são inseparáveis, caso se queira uma análise do espaço. "Tomados individualmente, representam apenas realidades parciais, limitadas, do mundo. Considerados em conjunto, porém, e relacionados entre si, eles constroem uma base teórica e metodológica a partir da qual podemos discutir os fenômenos espaciais em totalidade" (SANTOS, 1997, p. $52)$.

Como as ações do homem são dinâmicas, as relações entre as quatro categorias mudam ao longo do tempo, uma vez que, não são estáticas e respondem aos estímulos da 
sociedade. Daí a necessidade em estudá-las inseridas na noção de tempo.

“O movimento da totalidade social acarreta mudanças no equilíbrio entre as diferentes instâncias ou componentes da sociedade, modificando os processos, exigindo novas funções e atribuindo diferentes valores às formas geográficas” (SANTOS, 1997, p. 57).

A mudança estrutural se dá também pela mudança das formas e as alterações de velhas formas para adequação às novas funções são também uma mudança estrutural. As formas podem também envelhecer, e há dois tipos de envelhecimento, no aspecto físico ou social. No primeiro, o envelhecimento das formas ocorre pelo desgaste dos materiais, já no segundo aspecto, seu envelhecimento se deve ao desuso ou desvalorização, com a preferência social por outras formas. O envelhecimento social está relacionado ao quadro político, econômico, social e cultural (SANTOS, 2014).

Santos (2014, p. 75) reforça a necessidade em compreender o papel das técnicas no contexto das relações sociais, ao afirmar que "as formas não nascem apenas das possibilidades técnicas de uma época; dependem também das condições econômicas, políticas, culturais etc". Assim, podemos perceber que as técnicas não se dão de maneira homogênea no espaço.

\section{ASPECTOS DA ORGANIZAÇÃO ESPACIAL DO MUNICÍPIO DE DELMIRO GOUVEIA-AL E O LEGADO DO 'INDUSTRIAL DO SERTÃO'}

Após levantamentos científicos, visando a melhoria da navegação pelo rio São Francisco, o Governo Imperial optou pela construção da ferrovia, contornando assim, a Cachoeira de Paulo Afonso, um desnível natural do rio.

Em seguida, a construção da Estrada de Ferro Paulo Afonso (EFPA) foi iniciada em 1878, no município de Piranhas-AL. A EFPA fez parte do surto ferroviário brasileiro, durante o Segundo Reinado (1840-1889), período no qual houve grande investimento público na construção de ferrovias, e utilizou a mão- de-obra sertaneja, principalmente por retirantes da Seca de $1877^{5}$, que assolou o Sertão e obrigou muita gente a migrar para as margens do incansável São Francisco (SILVA, 2012).

A inauguração dos seus 116 km ocorre em 1883, ligando Piranhas-AL a Petrolândia-

\footnotetext{
${ }^{5}$ A Seca de 1877 foi emblemática não apenas no contexto social, com a perda de um terço da população, entre mortos e emigrados, somente na província do Ceará. A efeméride despertou o poder público para a questão da seca que realizou ações inéditas construindo açudes e barragens. Afetou também o ideário nacional, com a emergência do Nordeste como região-problema e o imaginário social, surgindo posteriormente várias obras literárias tratando a questão da seca. O período guarda uma conhecida frase de D. Pedro II, repetida várias vezes pela historiografia que, "doaria todas as joias da coroa para salvar a população da seca” (BRITO, 2013).
} 
PE, onde a navegação era retomada. Cumprindo seu objetivo de ligar o baixo e o alto São Francisco, pessoas e mercadorias eram transportadas pela ferrovia. Assim, a antiga Vila da Pedra (atual município de Delmiro Gouveia), por onde passava a EFPA, é inserida no meio técnico-científico, ver Figuras 2 e 3 (SILVA, 2012).

Com mudanças estruturais no meio de transporte nacional, o papel das ferrovias que vinha sendo relegado desde meados dos anos 1950 foi, notadamente no Governo Militar, a partir de 1964, que a supressão da ferrovia se deu com mais vigor, através da criação do programa de erradicação dos ramais ferroviários considerados antieconômicos. Entre os inúmeros quilômetros de ferrovias desativados, deixaram de operar ainda no primeiro ano da ditadura civil-militar, os $116 \mathrm{~km}$ da EFPA. Desde então, a estrutura rodoviária nacional se consolidou, sendo o principal meio de transporte até hoje (PAULA, 2001; SILVA, 2012).

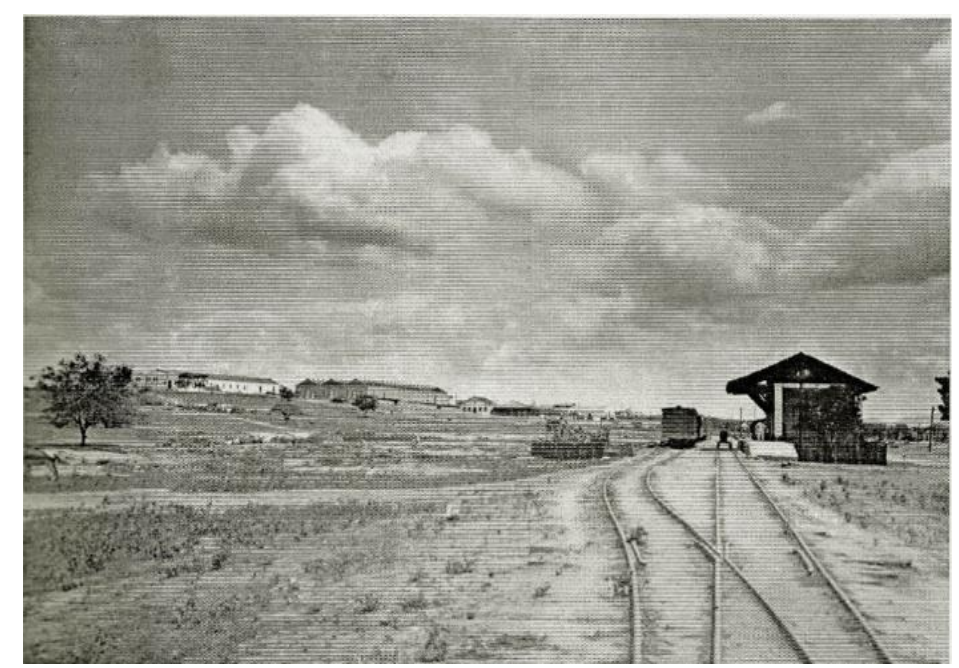

Figura 2: Estação da Pedra, da Estrada de Ferro Paulo Afonso, em segundo plano, a Fábrica de Linhas, em 1916.

Fonte: ALVES, 2014.

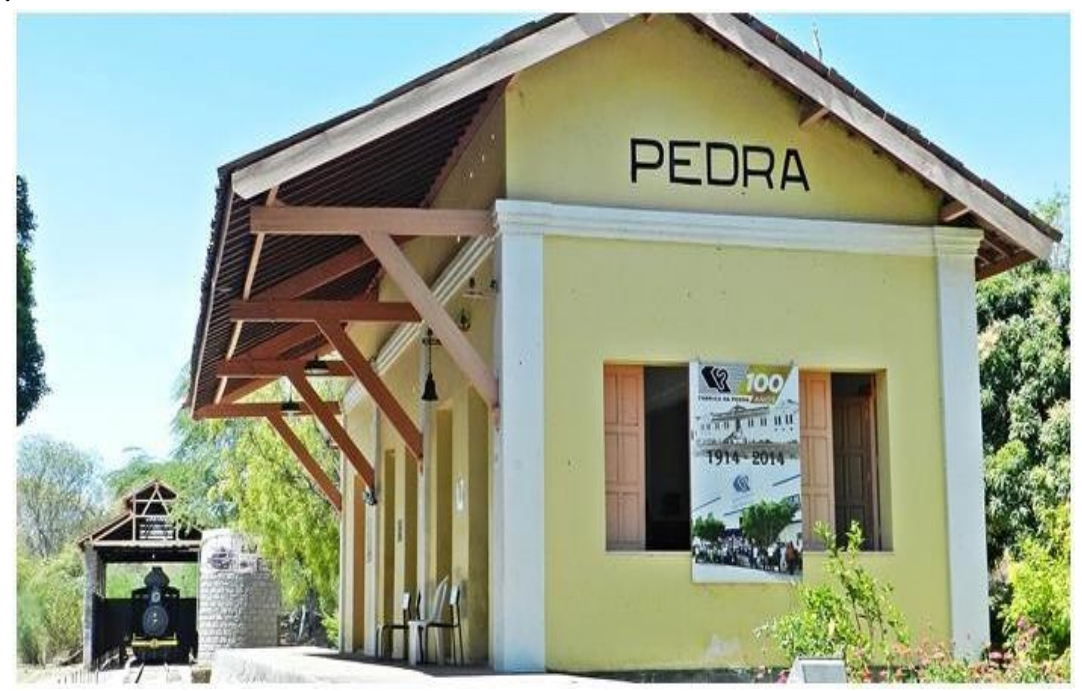

Figura 3: Prédio da antiga Estação da Pedra onde abriga atualmente o Museu Delmiro Gouveia.

Fonte: Foto do autor, 2015. 
Após a extinção da EFPA, a estação ferroviária da Pedra, onde floresceu em sua volta a antiga Vila da Pedra, manteve sua forma, mas perdeu sua função em transportar pessoas e cargas. O antigo prédio da estação da Pedra recebe uma nova função em 1989, quando é inaugurado no local o Museu Delmiro Gouveia. Destinado a preservar sua história, reúne objetos pessoais, fotografias e documentos da época de Delmiro, maquinário da antiga fábrica de linhas e uma locomotiva à vapor da extinta EFPA. A ideia de instituir um museu se deve ao grupo mineiro Cataguases quando adquiriu a fábrica nos anos 1980 (SANT'ANA, 1996).

Com a alteração de sua função, o antigo prédio da estação da Pedra, transformado em museu, é um exemplo do envelhecimento da forma no âmbito social, quando o papel das ferrovias é desvalorizado e a preferência política é materializada na expansão das rodovias no Brasil. Portanto, o antigo prédio onde abrigava uma estação ferroviária teve sua função alterada para manter-se na atualidade.

Aspecto semelhante ocorreu com a Usina Hidrelétrica de Angiquinho (Figura 4), que teve sua função alterada, deixando de ser uma forma destinada a produção de energia e fornecimento de água, para tornar-se, atualmente, numa instalação histórica através do tombamento por decreto de 2006 do estado de Alagoas. Entretanto, temos uma nuance entre Angiquinho e o antigo prédio da estação da Pedra, enquanto que esta última forma envelheceu socialmente, Angiquinho envelheceu fisicamente.

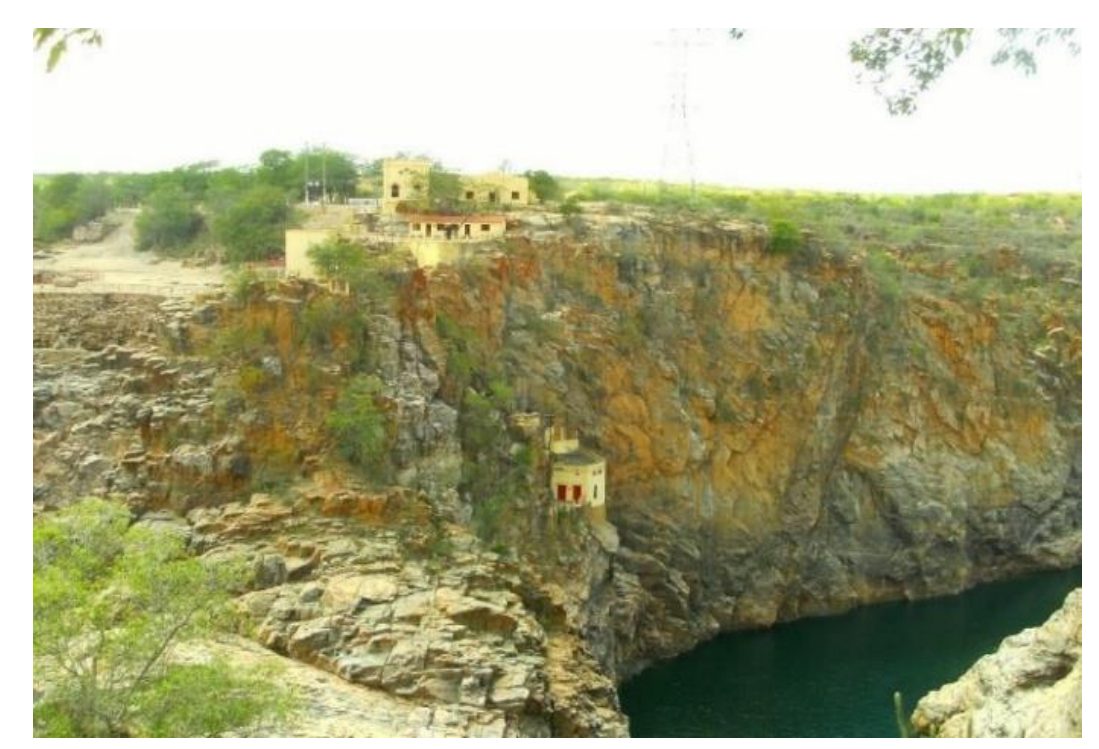

Figura 4: Usina Hidrelétrica de Angiquinho no município de Delmiro Gouveia-AL. Foto do autor, 2012.

A chegada de Delmiro Gouveia a antiga Vila da Pedra ampliou as suas formas técnico-científicas com a construção de Angiquinho e da fábrica de linhas, quando, através de suas atividades causaram uma reorganização espacial no local. Assim, a Vila que estava 
organizada na pecuária e comércio de couro, após sua chegada, passa a receber uma estrutura de equipamentos urbanos, com a presença de energia, água encanada, telégrafo e estradas.

A instalação da fábrica de linhas na antiga Vila da Pedra tornou sua configuração espacial mais complexa e estabeleceu novas relações entre a Vila e os lugares. É a partir da sua operação que a Vila tem uma relação mais dinâmica com o mundo, através de suas exportações de linhas, importação de maquinário europeu e matéria- prima do estado do Rio Grande do Norte (o algodão Seridó).

Podemos entender a instalação da fábrica de linhas na antiga Vila da Pedra, em 1914, como um processo, à medida que a indústria têxtil foi o primeiro setor industrial a se desenvolver no Brasil, a partir do final do século XIX. Na década de 1920, a indústria têxtil é o principal setor da indústria nacional. Durante a Segunda Guerra Mundial, com o Brasil intensificando a substituição de importações, Alagoas já contava no final da década de 1940, com 13 fábricas têxteis no segmento de fiação e tecelagem, o maior número já registrado no estado. Em Alagoas, essas fábricas concentravam-se no Litoral e às margens do São Francisco. (MAMIGONIAN, 2000; SANT'ANA, 1996; LESSA, 2013).

Após a morte de Delmiro, em 1917, até os dias de hoje, a Fábrica da Pedra (nome atual) passou pelo comando de diversos grupos empresariais, na produção de linhas, jeans e artigos de cama e mesa. A fábrica testemunhou mudanças estruturais no cultivo do algodão brasileiro nos anos 1990 e teve que se adaptar, passando a importar o algodão da Bahia, quando uma série de fatores contribuíram na queda drástica da produção algodoeira nordestina, entre eles, a praga do bicudo aliada a ausência de assistência técnica aos pequenos agricultores (BANCO DO NORDESTE, 2010).

Paralelo a isso, na mesma década, a produção algodoeira nacional está concentrada no Centro-Oeste, nas terras de cerrado, porém, ao contrário das plantações nordestinas, baseadas na agricultura familiar, o algodão no cerrado está em bases empresariais, com alto investimento tecnológico. É no oeste baiano, onde dispõe de terras de cerrado, que se concentra a produção algodoeira desse estado, contribuindo para a Bahia ser o principal produtor de algodão do Nordeste, com cerca de $79 \%$ da produção regional, em 2006, data do último Censo Agropecuário. No mesmo ano, Alagoas representa menos de 1\% na produção regional (BANCO DO NORDESTE, 2010).

\section{CONSIDERAÇÕES FINAIS}

As ações empreendedoras de Delmiro Gouveia deixaram um legado no município que leva seu nome, através da indústria e da modernização. As rugosidades no espaço 
geográfico municipal, contribuíram para o município de Delmiro Gouveia possuir nos dias atuais a maior população, com 48.096 habitantes, e o maior PIB da mesorregião do Sertão Alagoano, segundo dados do Censo 2010 do Instituto Brasileiro de Geografia e Estatística (IBGE) e da Secretaria de Planejamento do Estado de Alagoas. Fatores que foram relevantes na criação de novas formas no município, a exemplo da inauguração do Campus do Sertão da Universidade Federal de Alagoas em 2013, ofertando cursos de Engenharia, Pedagogia, Geografia, História, etc.

Delmiro iniciou os primeiros passos na industrialização do Sertão trazendo consigo inovações para a região, algumas destas inovações, sequer tinham se alargado pelo Litoral, onde estavam/estão as cidades mais ricas do Nordeste. Com o feito industrializante, trazendo um sopro de progresso, Delmiro derruba a ideologia do Sertão agrícola e desconstrói a imagem de uma região fadada a seca. Seu legado permanece, materializado no espaço geográfico local direta e indiretamente, através das antigas formas com novas funções e na chegada de novas formas ao município sertanejo.

Até hoje, a Fábrica da Pedra possui grande importância no município, segundo o presidente da Câmara de Dirigentes Lojistas, Michael Vilarindo, a fábrica é a terceira maior empregadora do município, atrás da prefeitura e comércio. Entretanto, por remunerar o trabalhador acima do salário mínimo, tem mais importância no município que o setor comerciário.

Adquirida pelo grupo alagoano Carlos Lyra, em 1992, a Fábrica da Pedra que emprega cerca de 430 trabalhadores, enfrenta mais um momento de dificuldades. Dada a recente crise econômica que o país enfrenta nos últimos anos, está com sua atividade paralisada desde março de 2016. A única fábrica têxtil que restou em Alagoas, com sua paralisação, prejudica fortemente os habitantes do município de Delmiro Gouveia que apesar da sua relevância no Sertão Alagoano possui uma tímida atividade econômica.

Entretanto, assim como o personagem Delmiro Gouveia, o município que leva seu nome procura resistir, e o faz buscando preservar seus feitos e manter sua memória viva e seu potencial de resiliência e resistência.

\section{REFERÊNCIAS BIBLIOGRÁFICAS}

ALVES, Sérgio. Empreendedorismo pioneiro e inovação organizacional no limiar do século XX: uma análise do legado de Delmiro Gouveia. In: DIÓGENES, Eliseu; ALVES, Sérgio; SILVA, Davi R. B. da. Delmiro Gouveia entre o mito e a realidade: seus empreendimentos e sua contextualidade no tempo e no espaço. 1. ed. Maceió: EDUFAL, 2014.

BANCO DO NORDESTE. Produção e área colhida de algodão no nordeste. Informe Rural 
Etene, Fortaleza, n. 17, p. 1-7, nov. 2010.

BRITO, Luciana. A fome: retrato dos horrores das secas e migrações cearenses no final do século XIX. Estação Literária. Londrina, v. 10, p. 111-125, jan. 2013.

ENCICLOPÉDIA DOS MUNICÍPIOS BRASILEIROS. v. 19. Rio de Janeiro: IBGE, 1957. Disponível em: 〈http://biblioteca.ibge.gov.br/visualizacao/livros/liv27295_19.pdf〉. Acesso em: fev. 2017.

GIMENES, Gabriela X. A Exposição Universal de Chicago e as imagens construídas sobre as Américas pelo jornal Chicago Tribune (1889-1894). In: ENCONTRO INTERNACIONAL DA ANPHLAC, 11, 2014, Niterói. Anais... Niterói: ANPHLAC, 2014. p. 1-15.

LESSA, Golbery L. Trama da memória, urdidura do tempo: ethos e lugar dos operários têxteis alagoanos. In: TENÓRIO, D. A.; LESSA, G. L. O ciclo do algodão e as vilas operárias. 1. ed. Maceió: EDUFAL, 2013.

LIMA JÚNIOR, Félix. Delmiro Gouveia: o Mauá do sertão alagoano. 2. ed. Maceió: Federação do Comércio do Estado de Alagoas, 1983.

MAMIGONIAN, Armen. Teorias sobre a industrialização brasileira. Cadernos Geográficos, Florianópolis, n. 2, p. 1-37, mai. 2000.

MARROQUIM, Adalberto. Terra das Alagoas. 1. ed. Roma: Miglione e Strini, 1922.

PAIVA FILHO, Arnaldo P. G. de. Rio Largo: cidade operária. 1. ed. Maceió: SENAI, 2013.

PAULA, Dilma A. de. As ferrovias no Brasil: análise do processo de erradicação de ramais. In: SIGLO Y MEDIO DE FERROCARRILES EN MADRID, 2, 2001, Madrid. Anais... Madrid: II Congreso de Historia Ferroviaria, 2001. p. 1-19.

ROCHA, Tadeu. Delmiro Gouveia: o pioneiro de Paulo Afonso. 4. ed. Maceió: Imprensa Oficial Graciliano Ramos, 2012.

SANT'ANA, Moacir M. de. Bibliografia anotada de Delmiro Gouveia: 1917 - 1994. 1. ed. Recife: Companhia Hidro Elétrica do São Francisco, 1996.

SANTOS, Milton. Por uma Geografia Nova: da crítica da Geografia a uma Geografia Crítica. 6. ed. São Paulo: Edusp, 2004.

Espaço e método. 4. ed. São Paulo: Nobel, 1997.

Metamorfoses do Espaço Habitado: fundamentos teóricos e metodológicos da

Geografia. 6. ed. São Paulo: Edusp, 2014.

SCHUMPETER, Joseph A. Teoria do desenvolvimento econômico: uma investigação sobre lucros, capital, crédito, juro e o ciclo econômico. (2. ed., 1934). Tradução de Maria Sílvia Possas. São Paulo: Nova Cultural, 1997.

SECRETARIA DE ESTADO DO PLANEJAMENTO E DO DESENVOLVIMENTO ECONÔMICO. Alagoas em mapas. 1. ed. Maceió: SEPLANDE, 2012.

SILVA, Davi Roberto B. da. A construção da estrada de ferro Paulo Afonso: fotografia e história. 1. ed. Maceió: IHGAL, 2012.

TENÓRIO, Douglas A. Um rio de história e um ninho de culturas. In: TENÓRIO, Douglas A.; DANTAS, Carmen L.; CAMPOS, Rochana e equipe. Rio São Francisco das Alagoas. 1. ed. Brasília: Senado Federal, 2011.

TICIANELI, Edberto. História da Ceal. 2016. Disponível em:

<http://www.historiadealagoas.com.br/historia-da-ceal.html >. Acesso em: fev. 2017.

Recebido em junho de 2016.

Aceito em agosto de 2017. 